\title{
Canonical correlations among morphological and yield traits in primocane-fruiting raspberries
}

P.M. Marchi ${ }^{1}$ I.R Carvalho ${ }^{2}$, Mini $^{3}$, V J. Szareski ${ }^{4}$, A J. de Pelegrin ${ }^{4}$ I.S. Pereira ${ }^{1}$ and L.E.C. Antunes ${ }^{1}$

${ }^{1}$ Empresa Brasileira de Pesquisa Agropecuária, Estação Experimental de Fruticultura de Clima Temperado, Pelotas, RS, Brasil

${ }^{2}$ Universidade Regional do Noroeste do Estado do Rio Grande do Sul, Ijuí, RS, Brasil

${ }^{3}$ Instituto Nacional de Investigación Agropecuária , Las Brujas, Departamento de Canelones, Uruguay

${ }^{4}$ Universidade Federal de Pelotas, Pelotas, RS, Brasil

Corresponding author: I.R. Carvalho

E-mail: carvalho.irc@gmail.com

Genet. Mol. Res. 19 (2): gmr18500

Received October 11, 2019

Accepted May 28, 2020

Published June 30, 2020

DOI http://dx.doi.org/10.4238/gmr18500

\begin{abstract}
Raspberry (Rubus idaeus) is an economically important crop, and its cultivation has expanded recently across temperate and subtropical regions of Brazil. There is no brazilian raspberry cultivar so far. Therefore, the indirect selection can be an useful tool to help during the breeding process. We evaluated linear and canonical correlations in primocane-fruiting raspberry cultivars in 2013 and 2014, in a completely randomized experimental design, with eight replications. The genotypes 'Alemãzinha', 'Heritage' and 'Fallgold' were evaluated during two harvesting seasons, autumn and spring. Canonical groups were established among morphological (Group 1) and yield (Group 2) traits. In Group 1, plant yield and fruit weight were evaluated; in Group 2 the productive period, plant height, stem diameter, dry mass of pruning and plant leaf area were assessed. The linear and canonical correlations among morphological, phenological, and yield traits varied according to harvesting season. The phenological and morphological traits had greater linear correlation with yield traits in autumn than in spring. Based on our findings, to obtain more productive raspberry genotypes, plant leaf area and dry mass of pruning should be prioritized in the indirect selection.
\end{abstract}


Key words: Rubus idaeus; Indirect selection; Small fruit breeding

\section{INTRODUCTION}

Raspberry (Rubus iadeus) is an important species included in the small fruits group (Bobinaite et al., 2012). The fruits are greatly appreciated for providing essential nutrients in human diet, with metabolic benefits for people's health (Singh et al., 2009). The raspberry growing area has expanded in temperate and subtropical regions of Brazil during the last few years (Curi et al., 2015; Marchi et al., 2019). The increasing demand for raspberries consumption brings several challenges, such as the characterization of the cultivars available in the country, and the study of tools to help the development process of brazilian cultivars.

In this regard, the indirect selection can provide useful information to improve the breeding process, especially considering that the selection of the best genotypes should encompass several traits simultaneously. Consequently, phenotypic correlations are imprtant to aid on the selection strategies development (Coimbra et al., 2000). If the selection practice takes into consideration only plant yield, the result may not be fully effective (Ezeaku et al., 2015). Pearson correlation is an analysis widely used to evaluate the relevance of one trait in relation to another (Carvalho et al., 2004) while the canonical correlation test is based on a multivariate statistical model, which correlates various groups of traits (Cruz et al. 2012). Both methods described can be helpful to optimize and simplify the breeding process.

Little is known about correlations of raspberries traits. Canonical correlations were studied in raspberry in order to identify associations among traits of mechanized harvest and fruit quality (Hall et al., 2002); some other studies were performed to evaluate linear correlations among bioactive compounds and yield traits (Stephens et al., 2009; Bobinaite et al., 2012). None of these studies identified correlations among phenological, morphological and yield traits for indirect selection in raspberries.

In order to improve the efficiency of raspberry breeding, this study aimed to evaluate linear and canonical correlations of primocane-fruiting raspberry cultivars.

\section{MATERIAL AND METHODS}

The experiment was carried out from Nov 2013 to Dec 2014, at Embrapa

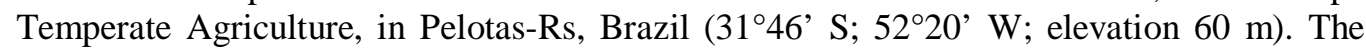
climate of this region is characterized as Cfa - subtropical with hot summer (Alvares et al., 2014). The raspberry genotypes tested in this trial were 'Alemãzinha' and 'Heritage', which produce red fruits; and 'Fallgold', which produces yellow fruits. These cultivars were chosen due to the availability of plants to run the trial, and they are all primocane-fruiting, resulting in two productive cycles, one during fall, and the other during spring/summer.

The experimental design was completely randomized, in a unifactorial design with three raspberry cultivars and eight replicates. Experimental units were composed of five plants, spaced 1.0 meter $(\mathrm{m})$ between rows, and $0.5 \mathrm{~m}$ between plants. The six-month old plants were transplanted from the greenhouse to outdoors into eight-liter pots filled with commercial substrate, and slow release fertilizer N-P-K, 15-09-12 formula, at a concentration of 5 g. $\mathrm{L}^{-1}$ was added. 
The experiment was installed in Nov 2013. Water was supplied by drip irrigation, with drippers spaced $0.15 \mathrm{~m}$. The tutoring was conducted through an armed system $1.20 \mathrm{~m}$ above ground level. Slow-release fertilizer was added every 120 days, at 5 g.L , $^{-1}$, formulation 15-09-12. Insects, pests, and diseases were controlled preventively with chemical treatments and removal of senescent and injured leaves.

The first pruning was performed during plant dormancy, after the fall development cycle (Aug 2014). Stems were reduced to the height of subapical buds (10 to $20 \mathrm{~cm}$ ); at the end of spring cycle, a second pruning was performed (Dec 2014). After each pruning, all plant material collected was used to determine the average dry mass of pruning (DMP), drying it in forced ventilation oven at $65^{\circ} \mathrm{C}$ until constant mass, followed by weighing with a digital scale with results expressed in grams. For both productive cycles, the days from transplant to flowering (DF) and harvesting (DH) were recorded (Surya and Rahman, 2012).

The morphological and yield traits measured were: average plant height $(\mathrm{PH})$, in $\mathrm{cm}$; average stem diameter (SD), in $\mathrm{mm}$; plant leaf area (PLA), obtained after each productive cycle with a leaf area meter equipment, in $\mathrm{cm}^{2}$ per plant; average fruit production (FP), determined by the ratio between mass of fruits harvested in each experimental unit and number of plants, measured per plant; average fruits number (FN), verified by the ratio between total number of fruits harvested and the number of plants in the plot, measured as fruits per plant; average fruit weight $(\mathrm{FW})$, obtained by the ratio between production and number of fruits harvested, measured in g; fruit size was measured through the longitudinal (FLD) and transversal (FTD) diameter, in mm, in which 20 fruits of each experimental unit were sampled. Harvests were standardized in three-days intervals until the end of each cycle. The harvesting period (HP) was accessed by summing the length of each harvesting cycles, expressed in days.

All the data were submited to an analysis of variance at 1 and $5 \%$ of probability. The Shapiro-Wilk's test was performed in order to verify the assumptions, and the Hartley's test for variance homogeneity (Ramalho et al., 2012). The traits results were submitted to Pearson's correlation, at $1 \%$ and 5\% probability. Estimates were made in each harvesting season, using the three raspberry genotypes and eight replicates data ( $\mathrm{N}=24$ observations). The linear correlations matrix was submitted to a multicollinearity diagnosis through the number of conditions (NC). Then, data were submitted to variance analysis and canonical correlations. The significance between groups was assessed by Chi-squared Statistic (Cruz et al., 2012). The canonical groups were established between yield components (Group 1) and morphological traits (Group 2). The Genes software was used to execute the statistical analysis (Cruz, 2013).

\section{RESULTS AND DISCUSSION}

A total of 66 associations were calculated in each season (Table 1). The traits evaluated were DMP, DF, DH, PH, SD, PLA, FP, FN, HP, FW, FLD, and FTD. In the upper diagonal are shown the autumn associations, with 18 significant correlations at $5 \%$ of significant the by $t$-test. The lower diagonal shows the spring associations, revealing 12 significant correlations.

During the autumn season, DF had high positive correlation with DH $(\mathrm{r}=0.82)$, as expected and explains that the sooner the flowering begins, the sooner is the harvesting. In this same season, there was a positive correlation between DF and FW $(r=0.54)$, and the 
high correlation between DH and FW ( $\mathrm{r}=0.70)$, suggests that later harvesting plants tend to have an improvement of FW. The same was not observed in the spring season, probably because the temperatures are higher than in autumn. Lower temperatures reduce metabolic rates, consequently, fruits development is slower, allowing greater accumulation of sugar and metabolic products, which results in fruits with higher weight. According to Criddle et al. (1997), metabolic rates and plants metabolic efficiency change continuously with temperature.

A moderate negative correlation was found for DF and HP in autumn $(r=-0.44)$, indicating that the longer it takes from planting to flowering, the shorter is the HP of the raspberry genotype studied (Table 1). It can be explained because raspberry is a temperate climate species (Souza et al., 2014), thus, the proximity of winter brings lower temperatures, which represent the signals for starting plants dormancy, reducing gradually the physiological processes and ending the reproductive stage. We also observed that, during the autumn season, plants with lower height $(\mathrm{PH})$ and stem diameter (SD), tend to anticipate harvesting (HP); and earlier harvesting plants produced higher FN. Intermediate negative correlations between $\mathrm{PH}, \mathrm{SD}$, and FN with the $\mathrm{PH}$ trait evidenced that.

The PLA presented moderate positive correlation with the morphological traits DMP and HP; and with the yield traits FN and FP. This evidenced that greater PLA is correlated with higher photo-assimilated production amount, confirmed by its correlation with DMP. In plants, photo-assimilated compounds are produced in leaves, which ones have a source role, and they are translocated to fruits, the drain (Taiz \& Zeiger, 2009). In this way, a good balance between source and drain is necessary to obtain good yields. This was confirmed in this study for the raspberry genptypes evaluated, once PLA improvement was favorable to extend the harvesting period, as well as to increase the FN and PY (Table $1)$.

The PH trait revealed a high positive correlation with SD $(r=0.73)$ and moderate with PLA $(r=0.49)$ during autumn, which means that larger stems are also more vigorous. Besides that, PH had moderate positive correlation with FN and FP $(r=0.63$ and $r=0.50$, respectively). As longer stems have more surface to emit flower buds, FN and HP can be increased. It is worth to mention that the PH and PLA are much easier traits to be evaluated than FN and PY. Besides that, the costs with harvesting are very significant in small fruit crops. The FW trait was not favored by $\mathrm{PH}$, in autumn or spring, according to the moderate negative correlation between these traits (Table 1).

We observed the influence of the morphological traits, PLA and PH, over some yield traits (PP, FN and PY), only in autumn. The same was not verified in the spring season probably due to the dormancy period that occurred between these two seasons, during which the plant breaks down starches molecules into soluble sugars, as a mechanism for could resistance, and as a source for the growing resumption in spring (Rodrigues et al., 2006). Consequently, the plant efficiency to accumulate and hydrolyze molecules, promoted by a good quantity of could, may have led to a better balance between the production of fruiting buds and vigour in autumn.

In the lower diagonal, which represents the spring associations, it can be observed that DH was positively correlated to DF, similar to what occurred in autumn, showing the same tendency in both harvesting seasons (Table 1). In spring, the morphological trait $\mathrm{PH}$ showed an influence to anticipate and to extend the harvest, according to its correlation with $\mathrm{DH}(\mathrm{r}=-0.40)$ and $\mathrm{HP}(\mathrm{r}=0.44)$. 
High positive correlations between FN and FP were found in autumn and spring. It means that yield is improved proportionally to a greater FN. The associations of FLD and FTD revealed the existence of a high positive correlation between these fruit dimension parameters, also in both season studied, evidencing a round shape of fruits from the raspberry genptypes 'Alemãzinha', 'Heritage', and 'Fallgold' (Table 1).

Also, with reference to fruit dimension, several yield traits revealed influence on FLD and FTD. The traits FN, FP, FW and FLD presented positive correlation with FTD; while only FP and FW improved FLD. Also, the plants with earlier harvesting provided increase of FLD. So, the improvement of each one of these traits by the plant is proportionally associated with their ability to increase FLD and FTD (Table 1).

Table 1. Phenotypic correlations between the yield components and morphological traits, evaluated in three raspberry cultivars, during the autumn (upper diagonal) and spring (lower diagonal).

\begin{tabular}{|c|c|c|c|c|c|c|c|c|c|c|c|c|}
\hline & DF & DH & HP & PH & SD & DMP & PLA & FN & FP & $\mathrm{FW}$ & FLD & FTD \\
\hline $\mathrm{DF}$ & - & $0.82 * *$ & $-0.44 *$ & -0.25 & -0.19 & -0.04 & -0.21 & -0.36 & -0.30 & $0.54 * *$ & 0.23 & 0.17 \\
\hline DH & $0.50^{*}$ & - & -0.30 & $-0.54 * *$ & $-0.50 *$ & -0.15 & -0.30 & $-0.41^{*}$ & -0.30 & $0.70^{* *}$ & 0.01 & 0.04 \\
\hline HP & -0.17 & -0.02 & - & 0.38 & 0.10 & -0.04 & $0.51^{*}$ & 0.27 & 0.24 & -0.22 & -0.24 & -0.34 \\
\hline PH & -0.14 & $-0.40^{*}$ & $0.44 *$ & - & $0.73 * *$ & 0.32 & $0.49 *$ & $0.63 * *$ & $0.55^{* *}$ & $-0.43^{*}$ & -0.04 & -0.21 \\
\hline SD & -0.03 & 0.29 & 0.34 & 0.19 & - & 0.023 & -0.01 & 0.29 & 0.24 & -0.33 & -0.05 & -0.31 \\
\hline DMP & 0.07 & 0.04 & -0.08 & 0.08 & -0.22 & - & $0.45^{*}$ & 0.32 & 0.30 & -0.01 & 0.36 & 0.25 \\
\hline PLA & 0.25 & 0.19 & 0.06 & -0.09 & -0.28 & 0.21 & - & $0.50 *$ & $0.49^{*}$ & -0.22 & 0.17 & 0.01 \\
\hline FN & -0.36 & -0.46 & -0.13 & 0.34 & 0.15 & 0.19 & -0.25 & - & $0.98 * *$ & -0.37 & -0.09 & 0.01 \\
\hline FP & 0.14 & -0.23 & -0.33 & 0.11 & -0.08 & 0.21 & 0.13 & $0.83^{* *}$ & - & -0.21 & -0.08 & 0.01 \\
\hline FW & 0.21 & 0.15 & -0.07 & $-0.45^{*}$ & -0.18 & -0.21 & 0.19 & -0.26 & 0.30 & - & 0.12 & 0.06 \\
\hline FTD & -0.31 & $-0.41^{*}$ & 0.08 & -0.06 & 0.01 & -0.35 & 0.13 & 0.29 & $0.42 *$ & $0.53 * *$ & - & $0.77 * *$ \\
\hline FLD & -0.01 & -0.31 & -0.01 & -0.01 & -0.06 & -0.01 & 0.11 & $0.43^{*}$ & $0.64 * *$ & $0.46^{*}$ & 0.69 * & \\
\hline
\end{tabular}

Yield components: DF, days to flowering; DH, days to harvesting; HP, harvest period; PH, plant height (cm); SD, stem diameter (mm); DMP, dry mass of pruning $\left(\mathrm{g}\right.$ plant $\left.{ }^{-1}\right)$; and PLA, plant leaf area $\left(\mathrm{cm}^{2}\right)$. Morphological traits: FN, fruits number; FP, fruits production $(\mathrm{g}$ plant $\left.^{-1}\right) ; \mathrm{FW}$, fruit weight ( $\left.\mathrm{g}\right)$; FLT, fruit longitudinal diameter $(\mathrm{mm})$; and FTD, fruit transversal diameter $(\mathrm{mm})$.

Related to the canonical correlations, phenotypic traits were used to form two groups. The "Group 1" included the yield components FP and FW. "Group 2" comprehended the morphological traits HP, PH, SD, DMP and PLA (Table 2). In autumn, two canonical correlation pairs were significant at $1 \%$ of probability by Chi-squared test $\left(\mathrm{x}^{2}\right)$. Consequently, they are both interesting for study, due to the dependence among the traits grouped in each one.

The coefficient of the first canonical pair in autumn showed that the reduction of HP, PH and SD, and the improvement of DMP, are determinant traits to obtain higher FW in raspberries (Table 2). In contrast, the coefficient of the second canonical pair revealed that increase of all morphological traits (Group 1) are related to higher FP. In other words, plants with higher FP are influenced by the extension of harvesting period and by vigorous plant growth (higher HP, PH, SD, PLA, and DMP). According to Curi et al. (2015), morphological traits, such as number, diameter and length of stems, do not influence yield improvement of raspberries under subtropical conditions. However, the authors concluded that a higher PLA is favorable to photosynthetic rates, and this can reflect in greater yield.

The correlation groups formed in spring also revealed significance for the two canonical pairs (Table 2). Coefficients of the first canonical pair showed high negative correlation among the morphological traits HP, PH, DMP, and PLA, and the yield trait FW. Thus, for the cultivars studied, the improvement in raspberries FW, in autumn and spring, occurred in plants with concentrated harvesting period, and not much vigorous. 
In most fruit species, including raspberries, the balance between photosynthetic sources (leaf area and other vegetative parts) and drains (mainly fruits), influence production quantity and quality (Marcon Filho et al., 2015). If there is a no balance in the source-drain relation, in which vegetative part are favored, the production quality may be affected, resulting in reduced FW.

For the second canonical pair in spring (Table 2), plants with higher HP, DMP, PLA, and SD tend to achieve higher FP. Considering these results, the costs of the raspberries breeding program could be optimized, because selection for harvesting could be estimated through the assessment of other easier to measure traits correlated with yield. An important detail is that raspberry harvesting has to be done in a 2-3 day interval, and the manpower cost is very high in small fruit crops (Curi et al., 2015).

Table 2. The loading of the yield components (Group 1) and morphological traits (Group 2) in the canonical correlations (r) between groups, for three raspberry cultivars, in autumn and spring.

\begin{tabular}{lcccc}
\hline Character & \multicolumn{3}{c}{ Canonical pair in Autumn } & \multicolumn{2}{c}{ Canonical pair in Spring } \\
\cline { 2 - 4 } & $\mathbf{1}^{\mathbf{( I )}}$ & $\mathbf{2}^{\mathbf{0}}$ & $\mathbf{1}^{\mathbf{0}}$ & $\mathbf{2}^{\mathbf{0}}$ \\
\hline Group 1 & & 0.6421 & 0.2708 & 0.9626 \\
FP & -0.7665 & -0.5899 & 0.9069 & 0.4211 \\
FW & 0.8074 & & & \\
Group 2 & & -8535 & -0.7059 & 0.7084 \\
HP & -0.5238 & 0.8652 & -0.9623 & 0.2717 \\
PH & -0.5030 & 0,7889 & -0.0491 & -0.9988 \\
SD & -0.6162 & 0,8391 & -0.8702 & 0.4928 \\
DMP & 0.5571 & 0,9795 & -0.6012 & 0.7992 \\
PLA & -0.2117 & 0.99 & 1.00 & 0.99 \\
R & 1.00 & $<0.0100$ & $<0.0100$ & $<0.0100$ \\
P & $<0.0100$ & &
\end{tabular}

\section{CONCLUSIONS}

The raspberry linear and canonical correlations among morphological, phenological, and yield traits depend on the harvesting season. The phenological and morphological traits present more linear correlations with yield traits in autumn than spring. The beginning of flowering and harvesting, the plant height, and plant leaf area should be focused on indirect selection for raspberries in autumn. To obtain the most productive raspberry genotypes in autumn and spring, morphological traits, such as plant leaf area and dry mass of pruning should be prioritized. Taller plants with larger diameter, higher dry mass of pruning, and shorter harvesting period should be considered to improve fruit weight in autumn; while in spring, shorter height, dry mass of pruning, plant leaf area, and productive period are more relevant.

\section{ACKNOWLEDGMENTS}

The authors would like to thank Embrapa Temperate Agriculture, CAPES (Coordination for the Improvement of Higher Level Personel), and to CNPq (National Cpuncil for Scientific and Technological Development) for funding support and scholarships. 


\title{
CONFLICTS OF INTEREST
}

\author{
The authors declare no conflict of interest.
}

\section{REFERENCES}

Alvares CA, Stape JL, Sentelhas PC, Gonçalves JLM et al. (2014). Köppen's climate classification map for Brazil. Meteorol. Z. 22: 711-728.

Bobinaite R, Viskelis P and Venskutonis PR (2012). Variation of total phenolics, anthocyanins, allagic acid and radical scavenging capacity in various raspberry (Rubus spp.) cultivars. Food Chem. 132: 1495-1501. https://doi.org/10.1016/j.foodchem.2011.11.137.

Carvalho FIF, Lorencetti C and Benin G (2004). Estimativas e implicação da correlação no melhoramento vegetal. Pelotas: Ed. Universitária UFPel, 142p.

Coimbra JLM, Guidolin AF, Carvalho IF De and Azevedo R de (2000). Correlações canônicas: II - análise do rendimento de grãos de feijão e seus componentes. Cienc. Rural. 30: 31-35. http://dx.doi.org/10.1590/S010384782000000100005 .

Criddle RS, Smith BN and Hansen LDA (1997). Respiration based description of plant growth rate responses to temperature. Planta. 201: 441-44.

Cruz CD, Regazzi AJ and Carneiro PCS (2012). Modelos biométricos aplicados ao melhoramento genético. Viçosa: Editora da UFV, 514p.

Cruz CD (2013). Programa GENES - Versão Windows, Aplicativo computacional em genética e estatística. Viçosa: UFV, 648p.

Curi PN, Pio R, Moura PHA, Sousa PH, et al. (2015). Production and quality of raspberries 'Batum' cultivated under cover plastic and two spacing in subtropical area. Cienc. Rural. 45: 1994-2000.

Ezeaku IE, Angarawai II, Aladele SE and Mohammed SG (2015). Correlation, path coeficiente analysis and heritability of grain yield components in pearl millet (Pennisetum glaucum (L.) R. Br.) parental lines. J. Plant Breed. Crop Sci. 7: 55-60. http://dx.doi.org/10.5897/JPBCS2014.0463.

Hall HK, Stephens MJ, Alspach P and Stanley CJ (2002). Traits of importance for machine harvest of raspberries. Acta Hortic. 585: 607-610.

Marchi PM, Carvalho IR, Pereira IS, Rosa TC, et al. (2019). Yield and quality of primocane-fruiting raspberry grown under plastic cover in southern Brazil. Sci. Agric. 76: 481-486.

Marcon Filho JL, Hipólito J De S, Macedo TA de, Kretzschmar AA, et al. (2015). Raleio de cachos sobre o potencial enológico da uva 'Cabernet Franc' em duas safras. Cienc. Rural. 45: 2150-2156. http://dx.doi.org/10.1590/0103$8478 \mathrm{cr} 20140995$.

Pritts M (2008). Primocane-fruiting raspberry production. HortScience. 43: 1640-1641.

Ramalho MAP, Santos JB, Pinto CBP, Souza EA, et al. (2012). Genética na agropecuária. Lavras: UFLA, 565p.

Rodrigues AC, Herter FG, Veríssimo V, Campos AD, et al. (2006). Balanço de carboidratos em gemas florais de dois genótipos de pereira sob condições de inverno ameno. Rev. Bras. Frutic. 28: 1-4. 10.1590/S010029452006000100003.

Singh D, Kumar K, Sharma VK and Singh M (2009). Expression of genetic variability and character association in raspberry (Rubus ellipticus Smith) growing in North-Western Himalayas. J. Hortic. Sci. 4: 28-31.

Souza VR. De, Pereira PAP, Silva TLT Da, Lima LC De O, et al. (2014). Determination of the bioactive compounds, antioxidant activity and chemical composition of Brazilian blackberry, red raspberry, strawberry, blueberry and sweet cherry fruits. Food Chem. 156: 362-368. doi: 10.1016/j.foodchem.2014.01.125.

Stephens MJ, Scalzo J, Alspach PA, Beatson RA, et al. (2009). Genetic variation and covariation of yield and phytochemical traits in a raspberry factorial study. J. Am. Soc. Hortic. Sci. 134: 445-452. 10.21273/JASHS.134.4.445.

Taiz L and Zeiger E (2009). Fisiologia vegetal. 4 ed. Porto Alegre: Artmed, 819p. 